\title{
Antifungal Properties of Some Essential Oils against Saccharomyces cerevisiae
}

\author{
Bachir raho $\mathrm{G}^{1 *}$, Bevilacqua $\mathrm{A}^{2}$, Corbo $\mathrm{MR}^{2}$, Sinigaglia $\mathrm{M}^{2}$ and Pignatiello $\mathrm{S}^{2}$ \\ ${ }^{1}$ Process Engineering and solution chemistry laboratory, Department of Biology, University of Mascara, Italy \\ ${ }^{2}$ Department of Food Science, Faculty of Agricultural Science, Foggia University, Italy
}

Received: 眥 August 08, 2018; Published: 制August 14, 2018

*Corresponding author: Bachir raho G, Process Engineering and solution chemistry laboratory, Department of Biology, University of Mascara, Italy

\begin{abstract}
To evaluate the antifungal activity of four essential oils against Saccharomyces cerevisiae in vitro, four commercial essential oils extracted from Thymus vulgaris, Echinacea Angustifolia, Rosmarinus officinalis and Salvia officinalis were tested at three different concentrations $(10,50$ or $100 \mathrm{ppm})$ for their antimicrobial activity against Saccharomyces cerevisiae using well diffusion method. $S$. cerevisiae was least susceptible to the essential oils. The diameter of zone inhibition ranged between 0 and $3 \mathrm{~mm}$. E. angustifolia, and $R$. officinalis oils appeared to be the most active, while T.vulgaris and S. officinalis oils exhibited most weak antifungal activity against S. cerevisiae. These findings increase the possibility of exploiting these essential oils as a safe alternative natural preservative.
\end{abstract}

Keywords: Essential oils; Antifungal Activity; S. cerevisiae

\section{Introduction}

Yeasts can have positive and negative effects on fermented products consumed by humans and animals. They are used as starter cultures in cheeses and bread, but they can also initiate spoilage in foods, such as yoghurt, fruit juice, salads, and mayonnaise [1]. Most spoilage incidents caused by yeasts are controlled by preservative systems. However, certain yeast species show resistance, especially to weak-acid preservatives. These strains belong to the fermentative yeast species Saccharomyces cerevisiae, Schizosaccharomyces pombe, Zygosaccharomyces spp., and Dekkera spp [2]. Saccharomyces cerevisiae is the most frequent spoiler of lemonades and fruit juices. This organism produces an alcoholic fermentation resulting in fermented off-flavour due to the presence of ethanol and carbon dioxide. Some strains also tolerate benzoates, sorbates and sulphates [3]. In recent years, interest in natural antimicrobial compounds has increased and numerous studies have been reported on the antimicrobial activity of a wide range of natural compounds [4]. The essential oils and extracts of many plant species have become popular and attempts to characterize their bioactive principles have gained momentum in many pharmaceutical and food-processing applications. The plant essential oils received major considerations about possessing a wide range of antimicrobial effects against different groups of pathogenic organisms. So, essential oils with antimicrobial activity are potential candidates, as natural antimicrobial preservatives, that can be used in controlling microbial food contaminations $[5,6]$. The aim of this study was to evaluate the antifungal effects of four commercial essential oil from Thymus vulgaris, Echinacea Angustifolia, Rosmarinus officinalis and Salvia officinalis against $S$. cerevisiae.

\section{Material and Methods}

\section{Essential Oils}

The essential oil of Rosmarinus officinalis, Thymus vulgaris, Echinacea angustifolia and Salvia officinalis was of commercial origin and purchased from Farmalabor (Canosa di Puglia, Italy) as liquid extract. The essential oil samples were stored in dark amber bottles with teflon-sealed caps.

\section{Yeast strain}

Saccharomyces cerevisiae EC1118 (Lallemand Inc.) was obtained from the German Collection of Microorganisms and Cell Cultures (Deutsche SammLung von Mikroorganismen und Zellkulturen GmbH, DSMZ, Germany). 


\section{Evaluation of Antifungal Activity}

Antimicrobial susceptibility testing was done using the well diffusion method to detect the presence of antifungal activities of the four commercial essential oils. The overnight culture of the microorganism's cultures were inoculated on Nutrient agar plates using sterilized cotton swabs. After media were solidified, three holes were made by using a sterilized cork borer each hole was filled with 10,50 or $100 \mathrm{ppm}$ of plant extract. Plates were incubated at $25{ }^{\circ} \mathrm{C}$ for 24 hours. The zones of inhibition were then recorded in millimeters.

\section{Results and Discussions}

Table 1: Antifungal activity as diameter of inhibition zone ( $\mathrm{mm})$ of the tested essential oils against $S$. cereviceae.

\begin{tabular}{|c|c|c|}
\hline Plant specie & Oil Concentration & S.cereviceae \\
\hline Thymus vulgaris & 10 & 2 \\
\hline & 50 & 2 \\
\hline & 100 & NI \\
\hline Echinacea Angustifolia & 10 & 2 \\
\hline & 50 & 2.5 \\
\hline & 100 & 3 \\
\hline Rosmarinus officinalis & 10 & 1 \\
\hline & 50 & 2.5 \\
\hline & 100 & 1 \\
\hline Salvia officinalis & 10 & 2 \\
\hline & 50 & 1 \\
\hline
\end{tabular}

Table 1 below summarises the antifungal properties of the four essential oils (T.vulgaris, E. angustifolia, R. officinalis, and S. officinalis). The yeast susceptibility to the essential oils, as determined by the well diffusion method, showed that oils with the weak inhibitory effects produced inhibition zones of 0-3 mm diameter. Among the four essential oils, E. angustifolia oils showed the highest activity, inhibiting the tested yeast with diameter of zone inhibition ranged between 2 to $3 \mathrm{~mm}$. S. officinalis oils were the weakest in activity with diameter of zone inhibition ranged between 1 to $2 \mathrm{~mm}$. The highest inhibition zone values ( $3 \mathrm{~mm}$ ) observed against $S$. cereviceae with 100 ppm E. angustifolia oils. While 100 ppm of T.vulgaris oil did not show any antifungal activity. Many previous studies have demonstrated inhibitory activities of thyme, rosemary, coneflower and sage [6-20] against various pathogens. Giordani R [21] studied the antifungal activity of essential oils of various chemotypes of T. vulgaris against Candida albicans. They reported significant activity of the essential oil of the thymol chemotype of T. vulgaris, with MIC of $0.016 \mu \mathrm{L} / \mathrm{mL}$. Such activity was attributed to the high concentration of thymol (63.2\%). In addition, both thymol and the essential oil of T. vulgaris, whose p-cymene and thymol contents are $36.5 \%$ and $33.0 \%$ respectively exhibited strong fungistatic and fungicidal activities against
Aspergillus, Penicillium, Cladosporium, Trichoderma, Mucor and Rhizopus. The inhibition effect of thymol was three times greater than the essential oil of T. vulgaris [22].

The essential oil of S. officinalis L. has been documented to have wide range of antimicrobial effects. The antimicrobial actions are suggested due to its chemical constituents dominated by camphor, 1,8-cineole, $\alpha$-thujone, and $\beta$-thujone [23-26]. The antifungal activity of $S$. officinalis is reported in several studies. Miladinović D [23] observed that the essential oil ( $2 \%$ and $1 \%$ in ethylene glycol) from the sage leaves was found to be active against Aspergillus niger. Khalil R [27] observed that the inhibitory effect of the sage essential oil on Candida albicans was total and definitive within a minimum of contact time and oil concentration. Similarly [28] reported that S. officinalis L. essential oil exhibited strong anticandidal activity against all strains of $C$. albicans with inhibition zone ranging from $40.5 \mathrm{~mm}$ to $19.5 \mathrm{~mm}$ and the MIC and MLC of the oil were determined as $2.780 \mathrm{~g} / \mathrm{L}$ against all test strains. Abu-Darwish et al (2013) reported that $S$. officinalis extracts have good inhibitory activities against dermatophytes in comparison with yeast and Aspergillus sp, especially Trichophyton rubrum and Epidermophyton floccosum, with MIC of $0.64 \mu \mathrm{L} / \mathrm{mL}$, in their study to the antimicrobial activity of sage extract against five yeast, seven dermatophytes and three Aspergillus strains. Similarly [29] reported that essential oil of sage has a broad spectrum of antifungal activity, against dermatophytes, Candida sp. and filamentous fungi. Antifungal activity of Rosemary essential oil is reported in other investigations. It was exploited by [30], who demonstrated a MIC of 60, 90, 120, 120 and $180 \mu \mathrm{g} /$ $\mathrm{mL}$ for Schizosaccharomyces pombe, Candida albicans, Rhodotorula glutinis, Yarrowia lipolytica and Saccharomyces cerevisiae respectively. Jiang Y [31] find a MIC of $1000 \mu \mathrm{g} / \mathrm{mL}$ and a MFC of $4000 \mu \mathrm{g} / \mathrm{mL}$ of rosemary oil on Aspergillus niger. The effect antifungal of rosemary oil is directly related to its main component $\alpha$-pinene, camphor, verbenone and 1, 8-cineole [32], which reported to have antimicrobial activity [33-36].

The antifungalactivities of essential oils of Echinacea Angustifolia were reported by some researchers. Binns SE [11] tested Echinacea extracts for antifungal activity against Saccharomyces cerevisiae and Candida spp. They showed phototoxic effects, inhibiting the growth of the two pathogenic yeasts, especially root extracts. Nonphototoxic effects were also examined, and the extracts still showed activity but it was reduced. The activity against these two fungi was determined to be by polyacetylenes and aklomides. Merali S [37] tested antifungal activity of five wild and three commercially used Echinacea varieties against pathogenic filamentous fungi (Trichophyton tonsurans, T. mentagrophytes, Microsporum gypseum, and Pseudallescheria boydii) and yeasts (Candida albicans and Cryptococcus neoformans) by bioassay with and without near UV light radiation. The results show that Root extracts of the threecommercial species of Echinacea (E. purpurea, E. pallida var. 
angustifolia, E. pallida var. pallida) inhibited the 5-LOX enzyme and E. pallida var. angustifolia was the most potent of the three. Sharma et al (2008) studied the antimicrobial properties of six different commercial Echinacea extracts against 15 different human pathogenic bacteria and two pathogenic fungi (Candida albicans and Trichoderma viride) and their results showed that fungi were either slightly sensitive to one or more extracts or were totally resistant. Similarly, [17] conducted a study where they screened the antimicrobial effect of ethanol extracts from different organs of E. angustifolia (herba, radix and rhizome) against five bacteria and four fungi (Alternaria alternata, Aspergillus fumigatus, Microsporum gypseum and Trichophyton terrestre). They found that Radix extract had the highest antifungal activity against filamentous fungi. MirRashed et al (2010) reported the antifungal activity of all Echinacea extracts tested against the wild type S. cerevisiae S288C. Three groups of phytochemicals are determined such as caffeic acid derivatives, polysaccharides and liphophilic alkamides, which are responsible for the genus medicinal properties [38]. Each constituent has shown individual bioactivity and contributes to the pharmacological activity of a given extract [39].

Echinacoside - a caffeic acid derivative- found in E. angistifolia oils has weak antimicrobial activity against Staphylococcus aureus [40]. In research conducted by Cruz et al (2014) on the effect of Alkamides from Echinacea on cell wall-membrane complex of Saccharomyces cerevisiae, they found that this antifungal activity can be attributed to the presence of alkamides in Echinacea extracts, with diynoic alkamides being more effective than dienic aklomides. Previous investigations have shown that many polysaccharides isolated from herbs possess biological activities [41-44]. In immunosuppressed mice, prophylactic treatment with Echinacea polysaccharides prior to infection with Candida albicans reduced renal Candida load by $80 \%$, compared to controls. Similarly, Echinacea treatment prior to infection with a lethal dose of Listeria monocytogenes reduced the bacterial counts in both liver and spleen by $95 \%$ compared to the levels in control mice. By between days 4 and 6 following infection, all untreated mice died, while $68 \%$ of those that received polysaccharides lived. In a similar study in immunodeficient mice, treatment with E. purpurea polysaccharide led to enhanced production of TNF-a and enhanced cytotoxicity against Leishmania enrietti and protected the mice against lethal infections with Listeria monocytogenes and Candida albicans [45]. The lowest level of antifungal activity of the tested essential oil against Saccharomyces cerevisiae founded in the present study could be explained by the absence of the active compounds or they are presented in low amount.

\section{Conclusion}

This study showed that the essential oil of T.vulgaris, E. angustifolia, $R$. officinalis, and $S$. officinalis have weak antifungal activity against Saccharomyces cerevisiae. Therefore, pharmacological and chemical tests are necessary to isolate and characterize their active compounds. Moreover, these plants extract should be investigated in vivo to better understand their safety, efficacy and properties.

\section{References}

1. Lowes KF, Shearman CA, Payne J, MacKenzie D, Archer DB, et al. (2000) Prevention of yeast spoilage in feed and food by the yeast mycocin HMK. Appl Environ Microbiol 66(3): 1066-1076.

2. Kregiel D (2015) Health Safety of Soft Drinks: Contents, Containers, and Microorganisms. Biomed Res Int, p. 1-15.

3. Juvonen R, Virkajärvi V, Priha O, Laitila A (2011) Microbiological Spoilage and Safety Risks in Non-Beer Beverages Produced in a Brewery Environment. VTT Tiedotteita-Research, Espoo, Finland.

4. Ayala-Zavala JF, del Toro-Sánchez L, Alvarez-Parrilla E, Soto-Valdez H, Martín-Belloso O, et al. (2008) Natural antimicrobial agents incorporated in active packaging to preserve the quality of fresh fruits and vegetables. Stewart Postharvest Review 4: 1-9.

5. Cowan MM (1999) Plant products as antimicrobial agents. Clin Microbiol Rev 12: 564-582.

6. Kahkha MRR, Amanloo S, Kaykhaii M (2014) Antiaflatoxigenic activity of Carum copticum essential oil. Environ Chem Lett 12(1): 231-234.

7. Panizzi L, Flamini G, Cioni PL, Morelli I (1993) Composition and antimicrobial properties of essential oils of four Mediterranean Lamiaceae. J Ethnopharmacol 39(3): 167-170.

8. Hili P, Evans CS, Veness RG (1997) Antimicrobial action of essential oils: the effect of dimethylsulphoxide on the activity of cinnamon oil. Lett Appl Microbiol 24(4): 269-275.

9. Valsaraj R, Pushpangadan P, Smitt UW, Adsersen A, Nyman U (1997) Antimicrobial screening of selected medicinal plants from India. J Ethnopharmacol 58(2): 75-83.

10. Hammer KA, Carson CF, Riley TV (1999) Antimicrobial activity of essential oils and other plant extracts. J Appl Microbiol 86(6): 985-990.

11. Binns SE, Purgina B, Bergeron C, Smith ML, Ball L, Baum BR, Arnason JT (2000) Light-mediated antifungal activity of Echinacea extracts. Planta Med 66(3): 241-244.

12. Hassawi D, Kharma A (2006) Antimicrobial activity of some medicinal plants against Candida albicans. J Biol Sci 6: 109-114.

13. Nzeako BC, Al-Kharousi ZS, Al-Mahrooqui Z (2006) Antimicrobial activities of clove and thyme extracts. Sultan Qaboos Univ Med J 6(1): 33-39.

14. López P, Sanchez C, Batlle R, Nerín C (2007) Vapor-phase activities of cinnamon, thyme, and oregano essential oils and key constituents against foodborne microorganisms. J Agric Food Chem 55(11): 4348-4356.

15. Pozzatti P, Scheid LA, Spader TB, Atayde ML, Santurio JM, et al. (2008) In vitro activity of essential oils extracted from plants used as spices against fluconazole-resistant and fluconazole-susceptible Candida spp. Can J Microbiol 54(11): 950-956.

16. Badiee P, Nasirzadeh A R, Motaffaf M (2012) Comparison of Salvia officinalis L. essential oil and antifungal agents against Candida species. journal of Pharmaceutical Technology and Drug Research 1: 7.

17. Bírošová L, Olejníková P, Vaverková Š (2012) Antimicrobial and antimutagenic activities of extracts from different organs of Echinacea angustifolia DC (Asteraceae). J Food Nutr Res 51(4): 201-206.

18. Sienkiewicz M, Łysakowska M, Denys P, Kowalczyk E (2012) The antimicrobial activity of thyme essential oil against multidrug resistant clinical bacterial strains. Microb Drug Resist 18(2): 137-148. 
19. Wendakoon C, Calderon P, Gagnon D (2012) Evaluation of Selected Medicinal Plants Extracted in Different Ethanol Concentrations for Antibacterial Activity against Human Pathogens. Journal of Medicinally Active Plants 1(2): 60-68.

20. Abu-Darwish MS, Cabral C, Ferreira IV, Gonçalves MJ, Cavaleiro C, Cruz MT, Al-bdour TH, Salgueiro L (2013) Essential oil of common sage (Salvia officinalis L.) from Jordan: assessment of safety in mammalian cells and its antifungal and anti-inflammatory potential. Biomed Res Int, pp. 538940.

21. Giordani R, Regli P, Kaloustian J, Mikail C, Abou LH (2004) Portugal, Antifungal Effect of Various Essential Oils against Candida albicans. Potentiation of Antifungal Action of Amphotericin B by Essential Oil from Thymus vulgaris. Phytother. Res 18: 990-995.

22. Klaric MS, Kosalec I, Mastelic J, Pieckova E, Pepeljnak S (2007) Antifungal activity of thyme (Thymus vulgaris L.) essential oil and thymol against moulds from damp dwellings. Lett. +Appl. Microbiol 44: 36-42.

23. Miladinović D, Miladinović Lj (2000) Antimicrobial activity of essential oil of sage from serbia. Facta Universitatis, Series: Physics, Chemistry and Technology 2(2): 97-100.

24. Raal A, Orav A, Arak E (2007) Composition of the essential oil of Salvia officinalis L. from various European countries. Nat Prod Res 21(5): 406411.

25. Hayouni el A, Chraief I, Abedrabba M, Bouix M, Leveau JY, Mohammed H, Hamdi M (2008) Tunisian Salvia officinalis L. and Schinus molle L. essential oils: their chemical compositions and their preservative effects against Salmonella inoculated in minced beef meat. Int J Food Microbiol 125(3): 242-251.

26. Hamidpour M, Hamidpour R, Hamidpour S, Shahlari M (2014) Chemistry, Pharmacology, and Medicinal Property of Sage (Salvia) to Prevent and Cure Illnesses such as Obesity, Diabetes, Depression, Dementia, Lupus, Autism, Heart Disease, and Cancer. J Tradit Complement Med 4(2): 8288.

27. Khalil R, Li ZG (2011) Antimicrobial activity of essential oil of Salvia officinalis L. collected in Syria. Afr J Biotechnol 10(42): 8397-8402.

28. Sookto T, Srithavaj T, Thaweboon S, Thaweboon B, Shrestha B (2013) In vitro effects of Salvia officinalis L. essential oil on Candida albicans. Asian Pac J Trop Biomed 3(5): 376-380.

29. Pinto E, Salgueiro LR, Cavaleiro C, Palmeira A, Gonçalves MJ (2007) In vitro susceptibility of some species of yeasts and filamentous fungi to essential oils of Salvia officinalis. Industrial Crops and Products 26: 135141.

30. Sacchetti G, Maietti S, Muzzoli M, Scaglianti M, Manfredini S, Radice M, Bruni R (2005) Comparative evaluation of 11 essential oils of different origin as functional antioxidants, antiradicals and antimicrobials in foods, Food Chemistry 91: 621-632.

31. Jiang Y, Wu N, Fu YJ, Wang W, Luo M, et al. (2011) Chemical composition and antimicrobial activity of the essential oil of Rosemary. Environmental Toxicology and Pharmacology 32: 63-68.
32. Moghtader M, Afzali D (2009) Study of the Antimicrobial Properties of the Essential Oil of Rosemary. American-Eurasian J Agric Environ Sci 5(3): 393-397.

33. Soković M, Van Griensven LJLD (2006) Antimicrobial activity of essential oils and their components against the three major pathogens of the cultivated button mushroom Agaricus bisporus. Eur J Plant Pathol 116: 211-224.

34. Zuzarte M, Gonçalves MJ, Cavaleiro C, Dinis AM, Canhoto JM, et al. (2009) Chemical composition and antifungal activity of the essential oils of Lavandula pedunculata (Miller). Cav Chem Biodivers 6: 1283-1292.

35. Koutsoudaki C, Krsek M, Rodger A (2005) Chemical composition and antibacterial activity of the essential oil and the gum of Pistacia lentiscus var. chia. J Agric Food Chem 53: 7681-7685.

36. Mazzanti G, Batinelli L, Salvatore G (1998) Antimicrobial properties of the linalool-rich essential oil of Hyssopus officinalis var. decumbens (Lamiaceae). Flavour Frag J 13: 289-294.

37. Merali S, Binns S, Paulin-Levasseur M, Ficker C, et al. (2003) Antifungal and antiinflammatory activity of the genus Echinacea. Pharmaceutical Biology 41(6): 412-420.

38. Kumar KM, Ramaiah S (2011) Pharmacological importance of Echinacea purpurea. International Journal of Pharma and Bio Sciences 2(4): 304314.

39. Singh N (2010) A comparison of both water and ethanol extracts prepared from Echinacea purpurea and Echinacea angustifolia on the response to Influenza $\mathrm{A} / \mathrm{PR} / 8 / 34$ infection in mice. Thesis master of science, Iowa State University.

40. Stoll A, Renz J, Brack A (1950) Isolierung und Konstitution des echinacosides, eines glykosids aus den wurzeln von Echinacea angustifolia D.C. Helv Chim Acta 33: 1877-1893.

41. Jin $M$, Huang $Q$, Zhao K, Shang P (2013) Biological activities and potential health benefit effects of polysaccharides isolated from Lycium barbarum L. Int J Biol Macromol 54:16-23.

42. Schepetkin IA, Quinn MT (2006) Botanical polysaccharides: macrophage immunomodulation and therapeutic potential. Int Immunopharmacol 6(3): 317-333.

43. Sun Y (2011) Structure and biological activities of the polysaccharides from the leaves, roots and fruits of Panax ginseng CA Meyer: An overview. Carbohyd Polym 85(3): 490-499.

44. Asressu KH, Tesema TK (2014) Chemical and antimicrobial investigations on essential oil of Rosmarinus officinalis leaves grown in ethiopia and comparison with other countries. J App Pharm 6(2): 132-142.

45. Steinmuller C, Roesler J, Grottrup E, Franke G, Wagner H, et al. (1993) Polysaccharides Isolated From Plant Cell Cultures Of Echinacea Purpurea Enhance The Resistance Of Immunosuppressed Mice Against Systemic Infections With Candida albicans and Listeria Monocytogenes. International Journal of Immunopharmacology 15: 605-614. 


\section{(C) (P) This work is licensed under Creative}

To Submit Your Article Click Here:

DOI: $10.32474 /$ CTBM.2018.01.000102

$\begin{gathered}\text { Current Trends on Biotechnology \& } \\ \text { Microbiology }\end{gathered}$
Assets of Publishing with us
- Global archiving of articles
- Immediate, unrestricted online access
- Rigorous Peer Review Process

